Обзоры, проблемы

\title{
ДОМАШНИЙ КРОЛИК Oryctolagus cuniculus var. domestica L. КАК МОДЕЛЬ В ИЗУЧЕНИИ ДОМЕСТИКАЦИИ И БИОМЕДИЦИНСКИХ ИССЛЕДОВАНИЯХ \\ (обзор)
}

\author{
Е.С. ЩУКИНА ${ }^{1}$, Г.Ю. КОСОВСКИЙ 1 , В.И. ГЛАЗКО1, 2 , И.С. КАШАПОВА 1 , \\ Т.Т. ГЛАЗКО1, 2
}

Домашний кролик Oryctolagus cuniculus var. domestica L. относится к тем немногим доместицированным видам, у которых дикий предковый вид существует одновременно с одомашненным (M. Carneiro, 2014), что позволяет изучать механизмы, лежащие в основе процессов доместикации. Следует отметить, что понимание генетических основ синдрома доместикации до сих пор остается неполным (M.A. Zeder, 2006-2017). Предполагается, что одомашнивание представляет собой уникальную форму симбиоза между человеком и доместицированными видами, формирующими общую нишу обитания (M.A. Zeder, 2012). Исследования симбиотических партнеров позволяют накапливать информацию о путях адаптации к такой нише, в том числе у человека. В этой связи важность изучения домашнего кролика трудно переоценить хотя бы потому, что на протяжении многих десятилетий он остается одной из основных моделей в биомедицинских экспериментах (K.M. El-Bayomi, 2013). Уникальные физиологические особенности кролика объясняют его широкое использование при выявлении закономерностей развития и течения многих заболеваний человека. В то же время мы не обнаружили работ, систематизирующих современные сведения по фундаментальной биологии этого доместицированного вида в сравнении с его дикой предковой формой. Задача настоящего обзора - суммировать данные о популяционно-генетической структуре (M. Carneiro, 2014; A.D. Stock, 1976), распределении геномных элементов (М. Carneiro, 2011), составе микробиомов (M.S. Gómez-Conde, 2009), морфометрических характеристиках и физиологических особенностях (С.Н. Боголюбский, 1959) домашнего кролика и предкового подвида европейского кролика, в том числе определяющих значение O. cuniculus var. domestica не только как хозяйственно ценного вида, но и как модельного объекта в различных областях биомедицины. Представленный сравнительный анализ позволяет выделить ряд фенотипических характеристик (J.L. Hendrikse, 2007; I. Brusini, 2018; P.S. Ungar, 2010), а также группу молекулярно-генетических маркеров геномной ДНК, дифференцирующих домашнего кролика от предкового вида (M. Sparwel, 2019). Изучение распределения аллелей различных мобильных генетических элементов, микросателлитов, отдельных структурных генов, вовлеченных в процесс доместикации домашнего кролика, может способствовать повышению эффективности управления генетическими ресурсами не только у этого вида, но и у других домашних животных, что необходимо как в медико-биологических исследованиях, так и для решения задач селекционной работы.

Ключевые слова: синдром доместикации, дикий кролик, домашний кролик, ДНК маркеры, эдогенные ретровирусы, полилокусное генотипирование, микробиота.

Исследование особенностей генетической структуры доместицированных видов составляет обязательное условие для разработок методов управления генетическими ресурсами хозяйственно ценных животных. Домашний кролик Oryctolagus cuniculus var. domestica L. относится к тем немногим доместицированным видам, у которых дикий предковый вид существует одновременно с одомашненным, что позволяет изучать механизмы, лежащие в основе процессов доместикации.

Вопросы кролиководства в последнее время активно разрабатываются, так как, по прогнозам «IndexBox, Inc.» (Великобритания), рост мирового производства крольчатины сохранит текущий тренд с ожидаемым ежегодным приростом объема рынка около +2,3 \% (до 1,8 млн т к 2025 году) (https://meatinfo.ru). В то же время мы не обнаружили работ, обобщающих современные сведения по фундаментальной биологии этого доместицированного вида.

Задача настоящего обзора заключалась в сравнительном анализе данных о популяционно-генетической структуре, распределении геномных 
элементов и фенотипических характеристиках домашнего кролика и его предкового подвида европейского кролика, а также о структуре микробиома и физиологических особенностях, определяющих свойства домашнего кролика как модельного объекта в различных областях биомедицины.

Домашний кролик как объект исследований и использования. Домашний кролик (Oryctolagus cuniculus var. domestica L.) достаточно давно разделяет общую нишу с человеком. Одомашнивание (доместикация) - количественный признак, диапазон которого варьирует от животных, испытывающих антропогенное давление, до максимально доместицированных и формирующих общую нишу с человеком (1). На сегодняшний день не существует единого мнения, что же представляет собой доместикация и доместикационный синдром, общий для таксономически удаленных видов (2-4). По мнению ряда исследователей (2), одомашнивание это уникальная форма симбиоза между человеком и доместицированными видами, сосуществующими в единой экологической нише.

Новый геологический период, в котором человеческая деятельность превратилась в планетарную преобразующую силу, получивший название антропоцен (5), влияет на приспособленность животных к условиям обитаниях посредством вмешательства в их жизненные циклы. В целом модель доместикации свидетельствует о том, что мишенью отбора служит не один вид, а их сообщество, то есть происходит коэволюция животных, человека и других симбионтов, в том числе входящих в состав микробиома у разных видов (1). Изучение механизмов доместикации вносит существенный вклад в понимание формообразования, искусственного отбора, методологии управления генофондами, породообразования и иных микроэволюционных процессов.

Европейский кролик (Oryctolagus cuniculus L.) - единственный признанный родоначальник домашнего кролика, которого в настоящее время считают важным сельскохозяйственным видом благодаря высокоценному диетическому мясу (оно усваивается организмом человека на 90 \%), высокой продуктивности, скороспелости, относительной неприхотливости в уходе, использованию в пушной промышленности, а также уникальным объектом биомедицинских экспериментов в связи с особенностями физиологии (6). Кролики как вид лабораторных млекопитающих существенно ближе генетически и физиологически к человеку. Кроме того, многоплодие и короткий репродуктивный период делают их наиболее удобной моделью для исследований по сравнению с другими доместицированными видами млекопитающих.

Из-за короткой продолжительности жизни, относительно небольших сроков беременности, многоплодия, низкой стоимости и доступности геномной и протеомной информации домашний кролик заполняет разрыв между мелкими лабораторными животными - мышами и крысами и более крупными животными (собаки и обезьяны) при необходимости экстраполировать экспериментальные данные, получаемые на модельных объектах, на человека. В ряде случаев это играет особо важную роль - например, при доклиническом тестировании лекарств и диагностических методов (7). Одним из наглядных вкладов кроликов в медицину служит открытие самого мощного гиполипидемического препарата статина (8). При развитии терапевтических методов достаточно давно стало очевидно, что многие болезни человека не могут быть должным образом исследованы на мелких мышевидных грызунах. Многие клинические испытания оказались неудачными - возможно, потому что эксперименты первоначально проводились именно на этих объектах. Кролик служит альтернативной моделью 
для изучения заболеваний человека и выяснения тех специфических вопросов, которые не могут быть решены на грызунах, что делает кролика ценным объектом как в медико-биологических, так и в фундаментальных исследованиях (9). Примером могут служить наследственные заболевания, широко распространенные у человека (аортальный атеросклероз, катаракта, гипертония, гипертрофическая кардиомиопатия, эпилепсия, остеопороз и т.д.). Получение трансгенных кроликов и особей с нокаутированными генами рассматривают как новый импульс для развития как терапевтических, так и диагностических стратегий в будущем (10).

Можно ожидать, что сравнительный анализ генома кролика и других млекопитающих еще более повысит его полезность как биологической модели. Изучение эпигенетических изменений в регуляторных геномных элементах будет способствовать обнаружению генных сетей, лежащих в основе адаптации животных к факторам экологического стресса, а секвенирование геномов кроликов позволит выявлять и сопоставлять критические регуляторные элементы этого процесса, структурные гены и их взаимодействия у грызунов, зайцеобразных и приматов.

Домашний кролик относится к числу наиболее поздно одомашненных видов и характеризуется исключительно высоким фенотипическим разнообразием. Известно более 200 пород кроликов (11), которых разводят как в коммерческих, так и в исследовательских целях (12-15). Область коммерческих интересов включает производство мяса, меха, шерсти и терапевтических белков, кроме того, кроликов используют в качестве домашних питомцев и компаньонов (16-18). На современном этапе продолжается селекционная работа, в которую существенный вклад вносят методы на основе применения ДНК маркеров, связанных с целевыми признаками (marker assistance selection, MAS), и геномной селекции с помощью выявления ассоциаций полиморфизма SNP структурных генов и регуляторных геномных элементов, контролирующих различные метаболические пути, с такими хозяйственно важными характеристиками, как мясная и шерстная продуктивность, репродукция животных, устойчивость к различным заболеваниям $(19,20)$. К настоящему времени выполнено полное секвенирование генома домашнего кролика (референтный геном представлен в GenBank NCBI, https://www.ncbi.nlm.nih.gov/assembly/GCF_000003625.3\#/def), сравнение полногеномных сиквенсов у домашнего и дикого кролика, выделены мононуклеотидные полиморфизмы (single nucleotide polymorphisms, SNP), выявлены и описаны геномные участки, полиморфизм которых ассоциирован с изменчивостью фенотипических характеристик животных $(21,22)$.

Таксономия домашнего кролика. Кроликов и зайцев относят к классу млекопитающие (Mammalia Linnaeus, 1758), отряду Lagomorph Brandt, 1855 (зайцеподобные) (всего 91 живущий вид), подразделенному на два семейства - Ochotonidae Thomas, 1897 (пищухи) и Leporidae Fischer, 1817 (зайцы, кролики) (23), которые эволюционировали на границе мелового и палеогенового периодов примерно 53 млн лет назад и находятся в той же основной группе млекопитающих, что грызуны и приматы (24). Видовые особенности строения органов и систем организма служат основанием для разделения кроликов и зайцев на два весьма схожих внешне, но отдельных вида. Кариотип у этих двух видов разный: у кроликов - 44 хромосомы, у зайцев - 48 (25-28).

История происхождения домашнего кролика. Предполагается, что приручение кроликов началось примерно 12 тыс. лет назад (29). Первые документальные записи о диких предках домашнего кролика, 
вовлеченного в процесс одомашнивания из географически ограниченной популяции Пиренейского полуострова и юго-запада Франции, созданы римлянами. Археологические данные показывают, что на этих территориях кролики широко использовались в период палеолита, мезолита и раннего $(30,31)$.

Есть исторические свидетельства того, что кролики были первыми животными, содержащимися в неволе на Пиренейском полуострове во время римской оккупации в I веке до н.э., где их выдерживали в больших корпусах для производства мяса (32). Марк Теренций Варрон (Marcus Terentius Varro), римский ученый-энциклопедист и писатель I века до н. э., содержал кроликов совместно с зайцами в лепорариях (клетках для содержания диких животных) (33) и откармливал до убоя (34), однако такая форма содержания существенно не влияла на поведенческие характеристики животных (35).

Исторические записи дают основание предположить, что направленная селекционная работа с кроликами, вероятно, началась около 600 года н.э. во французских монастырях по указу Папы Григория I Великого (Gregorius PP. I), утверждавшего, что тушки новорожденных крольчат не следует воспринимать как мясо, поэтому их можно употреблять в пищу во время поста $(11,32,36)$. Позже были выявлены многочисленные ошибки цитирования написанного латынью манускрипта конца VI века. Таким образом, идея о том, что во время поста крольчатина пользовалась популярностью, не подкреплена документально (37).

Известно, что кроликов намеренно завозили на территорию Европы в середине X века, так как уже тогда их мясо считалось деликатесом (36). Первые морфологические изменения скелета (затылочных костей, мечевидных отростков грудной кости, акромионов лопаток) совпадают с ранними данными о кроликах как домашних животных (XVIII век) (36).

Одомашнивание кроликов, как и других видов, было результатом непрерывного динамичного процесса, который отражает постепенные взаимодействия между людьми и животными (38). Необходимо рассматривать одомашнивание и связанные с ним биологические изменения как единый процесс (3). Он включает отношения человека и доместицируемых животных и преобразование этих отношений в пространстве и времени, в том числе интенсивность давления искусственного отбора, влекущего как изменения генетической структуры, так и появление новых морфологических форм у рассматриваемых объектов. На кроликов охотились во II тысячелетии до н.э., помещали в римские лепорарии, перевозили на средиземноморские острова, содержали в искусственных условиях, способствовали их размножению при клеточном содержании. В результате только в XVIII веке кролики приобрели первые фенотипические признаки доместицированных (отличающие этих особей от диких), и их стали разводить в качестве домашних животных. Ни один из перечисленных этапов не может классифицироваться как специальный «шаг» одомашнивания, но в совокупности у кроликов они сформировали комплекс признаков, соответствующих домашним животным (37).

C начала IX века благодаря финикийским торговцам в Средиземноморье (Плодородный полумесяц) началось глобальное распространение кроликов в качестве домашних животных, которых разводили на мясо и шкурки. Позже (в средние века) кроликов завезли на Британские и другие острова северо-восточной части Атлантического океана, а также в Австралию, Чили, Новую Зеландию, Северную и Южную Африку.

Современные породы кроликов характеризуются широким феноти- 
пическим разнообразием, ассоциированным с комплексом сложных молекулярно-генетических механизмов (11). Домашние кролики значительно отличаются от диких предков и имеют множество морфологических вариаций по таким признакам, как живая масса, конституция, качество и окраска волосяного покрова, длина уха, строение черепа, изменение размеров головного мозга и пр., а также поведенческие черты, такие как снижение уровня страха и агрессивности (39).

Морфологические и анатомические различия доместицированного кролика и дикого предка. Доместицированные формы кроликов отличаются от дикого предка морфологией затылочных костей, мечевидного отростка грудной кости, акромиона лопаток, позвонков (отростки более разветвленные и утолщенные), нижней челюсти и положением слухового прохода у кроликов с одним повисшим ухом (полувислоухие). Соотношение живой массы диких и одомашненных кроликов составляет $1: 2,17$, длины тела $-1: 1,41$, объема черепа $-1: 1,15$. Таким образом, размер черепа и, следовательно, головного мозга, как показывает оценка промеров тела у диких и домашних особей, увеличились незначительно, что объясняется малой шириной черепа относительно его длины у всех домашних кроликов. Для одомашненных видов характерно отсутствие на костях резко выраженных бугров и шероховатостей в местах прикрепления мышц, что обусловлено общим ослаблением мускулатуры (40).

При увеличении размеров тела у кроликов наблюдаются изменения шейных позвонков: по степени выраженности поперечных отростков третий позвонок становится похожим на четвертый, который, в свою очередь, приближается по форме к пятому (40).

Формообразование, морфологические различия. Наиболее информативно характеризует морфологическое разнообразие череп с учетом его сложной организации уже на стадии эмбрионального развития (нервный гребень, глоточная арка, дерматокраниум и эндокран) $(40,41)$. Обнаружено, что общее число гетерохронных (происходящих с расхождением по времени, неравномерно) событий, приводящих к изменениям размеров и формы органов и их функций в эволюционных временных масштабах, велико у собаки, кошки, домашней лошади, овцы, ламы и кролика (42). В связи с тем, что морфологические преобразования при переходе от дикого предка к доместицированному представителю опосредованы, в том числе некоторыми видоспецифическими процессами, и проявляются с различной интенсивностью, установление общих анатомических признаков, характерных для домашних животных, не следует принимать как показатель «синдрома одомашнивания» (43). Видоспецифичное строение черепа и изменение его пропорций в процессе роста, вероятно, представляет собой один из наиболее важных факторов, обеспечивающих морфологическое разнообразие (44).

Неизометричный (аллометрический) рост формирует потенциал для морфологической изменчивости (45), так как даже при незначительных изменениях размера тела приводит к различным пропорциям у животных (46). Напротив, изометрический рост подразумевает, что две особи разного размера, как правило, схожи в пропорциях тела. Разность размеров черепа кроликов, одомашненных в средние века (32), не определена количественно, но фенотипически их черепа значительно различаются (11). Высота венечного шва указывает на положительную аллометрию у всех исследованных особей, что предположительно связано с ускоренным ростом в постнатальный период. Отсюда следует, что синдром одомашнивания для кролика, 
по-видимому, характерен только в период эмбриогенеза (47).

Сравнительные морфометрические показатели диких (Oryctolagus cuniculus L.) и доместицированных кроликов (Oryctolagus cuniculus var. domestica L.) (M士SEM) (48)

\begin{tabular}{l|c|c|c|c}
\hline \multicolumn{1}{c|}{ Вид } & $\begin{array}{l}\text { Живая } \\
\text { масса, кг }\end{array}$ & $\begin{array}{l}\text { Объем } \\
\text { мозга, мл }\end{array}$ & $\begin{array}{l}\text { Уменьшение минда- } \\
\text { левидного тела, \% }\end{array}$ & $\begin{array}{c}\text { Объем медиальной } \\
\text { лобной коры, \% }\end{array}$ \\
\hline $\begin{array}{l}\text { Домашний кролик } \\
\text { Дикий предок } \\
\text { домашнего кролика }\end{array}$ & $4,12 \pm 0,25$ & $9,55 \pm 0,35$ & 10,1 & 12,1 \\
\hline
\end{tabular}

Выявлено снижение объема мозга относительно размеров черепа у домашних животных по сравнению с их дикими предками (48). Так, несмотря на большую живую массу домашних кроликов по сравнению с дикими (табл.), они обладают незначительно бо́льшим абсолютным размером мозга (см. табл.), сокращение правого и левого миндалевидного тела у доместицированного кролика было больше, объем правой и левой медиальной лобной коры увеличился. Это может быть одним из факторов снижения страха и агрессивности по отношению к человеку со стороны доместицированных видов, так как уменьшение размеров миндалины при относительном увеличении медиальной префронтальной коры у домашних животных, в том числе у кроликов, по сравнению с дикими особями влечет изменения безусловного рефлекторного поведения $(49,50)$. Например, у кроликов, приспособленных к жизни в неволе и к тесному контакту с человеком, проявление защитного рефлекса снижено и опосредовано отсутствием необходимости типа поведения «бой или бегство» $(51)$.

Данные о средних показателях размеров черепа и зубных дуг свидетельствуют о том, что у диких кроликов череп несколько шире и короче, чем у домашних. Домашние кролики имеют относительно длинный череп с носовой костью, выступающей вперед над резцами, тогда как у диких кроликов череп и носовая кость относительно короткие. Удлинение корней резцов и заболевания типа пародонтоза чаще наблюдаются у домашних кроликов (52-54). Рентгенограммы выявляют у домашних кроликов относительно высокие коронки по сравнению с дикими животными, что обусловлено разным характером питания $(55,56)$ и, возможно, также зависит от антропогенных факторов, воздействующих на животных (55). Зубы с длинными коронками и коротким корнем компенсируются интенсивным истиранием во время приема пищи, свойственным грызунам, и рассматриваются как эволюционная адаптация к высокой жесткости (абразивности) растений вследствие повышенного содержания кремнезема (характерного для фитолитов в травах) (52, 57-59).

У домашнего кролика выявлено смещение точек прикрепления мышц, например положение затылочного бугорка. Выемка угла нижней челюсти (antegonial notch of the mandible) находится на вертикальной линии относительно последних моляров у диких кроликов, тогда как у домашних она расположена сзади. Диастема между двумя передними резцами также зависит от изменения формы черепа. Эволюция черепа и нижней челюсти у кроликов регулировалась экологической адаптацией (60), включая локомоцию (перемещение животных в пространстве, обусловленное их активными действиями) (61) и типы питания $(62,63)$. Постоянный износ зубов с длинными коронками и коротким корнем в основном связан с абразивным питанием вследствие повышенного присутствия лигнина, целлюлозы и твердых силикатных фитолитов в травах и других растениях (64). Ветвь нижней челюсти выше относительно положения углового отростка, который сдвинут дорсально, что приводит к уменьшению расстояния между сус- 
тавами челюсти и мышцами углового отростка (глубокая и поверхностная жевательная мышца musculus masseter) у домашних кроликов по сравнению с дикими (65). Часть нижней челюсти, которая лежит вентральнокаудально к выемке угла нижней челюсти (доходит до конца задней дорсальной точки углового отростка), у домашних кроликов более выражена, чем у их диких предков. Дикие кролики отличаются от домашних сильно развитыми челюстными мышцами и увеличенной силой прикуса, что обеспечивается меньшей длиной черепа и вертикально расположенными мышцами челюсти, тогда как в удлиненном черепе мышцы располагаются под углом и сила укуса уменьшается (66). Вследствие употребления кроликами большого количества сена (67) происходит ретроградное удлинение корня зуба, что приводит к различным патологическим процессам и снижению аппетита $(68,69)$.

Разнообразие микробиоты кишечного тракта диких и доместицированных кроликов. Развитие микробиоты кишечника млекопитающих начинается с колонизации стерильного желудочно-кишечного тракта новорожденного животного бактериями посредством вертикального переноса от матери к потомству (70). Бифидобактерии играют ключевую роль в различных биологических процессах, таких как подавление развития гнилостных и болезнетворных микроорганизмов, а также способность к перевариванию углеводов (71).

Bifidobacterium longum и Bifidobacterium adolescentis присутствуют соответственно у 95,5 и 91,0 \% всех видов млекопитающих, Bifidobacterium pseudolongum и Bifidobacterium bifidum - у 85,0 \%. Установлено, что бифидобактериальное биоразнообразие, в том числе обилие в микробиоме таких видов, как B. magnum, B. bifidum, B. boum, B. mongoliense, B. new_taxa_10, B. new_taxa_50, B. new_taxa_23, B. new_taxa_59, B. new_taxa_54 (72), у одомашненных видов выше, чем у диких, что подтверждает гипотезу о том, что контакт с человеком, образ жизни в неволе и давление искусственного отбора способствуют приобретению млекопитающими новых бифидобактериальных таксонов.

У диких кроликов охарактеризованы 58 различных типов микробиома (72), которые отличаются от таковых у домашних. Особенности питания диких кроликов в значительной степени обусловлены их ареалом (73), доступностью кормовых ресурсов, давлением хищников и плотностью популяции. Травы с высоким содержанием структурных полисахаридов служат им основным источником корма (74).

Ферментативные показатели, значения концентрации и разнообразия бактериального сообщества желудочно-кишечного тракта диких и домашних кроликов имеют значимые различия: $\mathrm{pH}$ слепой кишки диких кроликов более кислый, содержания аммиака ниже, а концентрация летучих жирных кислот повышена относительно соответствующих показателей у домашних кроликов (75).

Валериановая кислота, продуцируемая микробиомом кишечника, обнаружена у 87 \% домашних кроликов и только у 68 \% диких. Присутствие изобутирата и изовалериановой кислоты характерны только для диких кроликов, причем выявляется лишь у $25 \%$ животных. Несмотря на то, что молярная доля ацетатов у диких кроликов ниже, доля бутиратов выше по сравнению с соответствующим показателем у одомашненных (75).

Известно, что у домашних кроликов количество растворимой клетчатки в рационе влияет на бактериальное разнообразие (75). Бактериальные профили различаются не только между дикими и домашними животными, но и между группами с неодинаковым типом питания (малое и большое 
количество растворимых волокон). Различия в обилии бактерий у домашних кроликов зависит от доли растворимой клетчатки в рационе (большое поступление легкоусвояемых веществ в слепую кишку способствует размножению бактерий) $(76,77)$. У диких особей сухое вещество (в расчете на 1 кг живой массы) усваивает на 55 л лучше, чем у доместицированных кроликов (соответственно 58 и 37 г сухого вещества на 1 кг живой массы) (78).

Генетические преобразования в процессе доместикации. Как отмечалось выше, европейский кролик (O. cuniculus) - единственный признанный родоначальник домашних кроликов. Этот вид распространен на Пиренейском полуострове, где примерно 1,8 млн лет назад произошло его расхождение на два подвида - O. cuniculus algirus, обитавший в юго-западной части Пиренейского полуострова, и O. cuniculus cuniculus, ареал которого включал северо-восток Пиренейского полуострова и Францию (21).

Несмотря на то, что вторичный контакт в плейстоцене привел к генетическому сходству обоих подвидов, O.c. algirus и O.c. cuniculus coхраняют выраженную дифференциацию (79). Выявлены существенные различия по полиморфизму участков хромосомы $\mathrm{X}$ в перицентромерном районе и дистальных участках, прилегающих к теломерам. Предполагается, что именно перицентромерная область Х-хромосомы может быть вовлечена в детерминацию элементов репродуктивной изоляции между двумя подвидами (80).

Известно, что степень внутрипородного и видового генетического полиморфизма по некоторым ДНК маркерам у кроликов составляют 0,2 \% (9), а от дикого предка современный кролик отличается на $60 \%$. Породы кроликов сравнительно молодые, коэффициент инбридинга субпопуляций относительно всей популяции (корреляция между случайно отобранными гаметами в пределах субпопуляции FST) (81) равен 17,9 \%. Это дает основания предполагать, что кролики, которые были предшественниками пород, содержались в виде закрытых генофондов, что способствовало накоплению породных популяционно-генетических различий (21). Результаты ретроспективного анализа популяционно генетических процессов показывают (82), что начальная популяция кроликов, вовлеченная в доместикацию, насчитывала менее 1200 особей (9).

Изменения, которые были обнаружены в таких структурных генах, как GPC3 (https://www.genecards.org/cgi-bin/carddisp.pl?gene=GPC3) и GPC4 (https://www.genecards.org/cgi-bin/carddisp.pl?gene=GPC4), кодирующих белки Glypican-3 и Glypican-4, вовлеченные в контроль клеточного деления, указывают на влияние искусственного отбора $(83,84)$. Генные сети, участвующие в контроле клеточного деления, в том числе гены $G P C 3$ и $G P C 4$, могут быть опосредованной мишенью отбора, поскольку размер тела исторически представляет собой первый селекционируемый признак у кроликов (32).

Одомашнивание кролика, судя по имеющимся данным о гаплотипах D-петли митохондриальной ДНК, видимо, стало причиной заметной потери части генетического разнообразия, как и у большинства одомашненных видов. Эффект бутылочного горлышка - общая черта одомашнивания, которое приводит к снижению генетической изменчивости по митохондриальной ДНК, что коррелирует со уменьшением эффективности отбора (85). Наблюдается постоянное снижение генетической изменчивости по микросателлитным локусам, митохондриальной ДНК и гену, кодирующему фактор транскрипции (Sex-Determining Region Y Protein, SRY) (https://www.genecards.org/cgi-bin/carddisp.pl?gene=SRY, 86), что, вероятно, объясняется малыми популяциями кроликов, которых исторически разводили изолированно 
(9). Для домашнего кролика характерна повышенная экспрессия генов sox6 (фактор регуляции транскрипции SOX6) (https://www.genecards.org/cgibin/carddisp.pl?gene=SOX6), а также prom 1 (Prominin 1) (https://www.genecards.org/cgi-bin/carddisp.pl?gene=PROM1\&keywords=PROM1), кодирующего антиген CD133. Оба этих гена вовлечены в модуляцию развития мозга, и уровни их экспрессии были выше у доместицированных видов (87).

Некоторые из известных генетических процессов, ассоциированных с одомашниванием и связанных с фенотипом, происходят в одних и тех же генах у разных видов домашних животных. Например, определенный окрас шерсти у собак (88), свиней (89), лошадей (90) и перьев у кур (91) ассоциирован с мутациями гена, кодирующего агути-меланокортиновый 1 рецептор (MC1R) (92). У лабораторных линий мышей обнаружена мутация по гену ASIP (Agouti Signaling Protein) в области промотора, связанная с ретровирусной вставкой, которая приводит к появлению у мыши черно-коричневого фенотипа. У кроликов, как полагают, существуют три аллеля $A S I P$, включая аллель $a t$, обусловливающий черно-коричневый цвет шерсти (93).

У домашних кроликов повышенная экспрессия характерна для Periplakin (PPL) (цитоскелет-ассоциированный белок) (94), пониженная для myosin 5C (MYO5C, фибриллярный белок, один из главных компонентов сократительных волокон мышечной ткани) (95). Несмотря на это, изменения последовательностей цис-элементов, регулирующих экспрессию этих генов, не выявлены $(87,96)$. Известно, что показатели генетической изменчивости (гетерозиготность, доля полиморфных локусов, генетические расстояния) у домашнего кролика (по результатам исследования неравновесного сцепления аллельных вариантов ряда микросателлитов) ниже по сравнению с дикими $(9,97)$. В то же время по ряду других геномных элементов наблюдается повышенный полиморфизм. Так, у некоторых линий домашнего кролика выявлено большое число аллельных вариантов по белкам спермы (98).

Вероятно, различие уровней экспрессии некоторых генов у домашних животных и их диких сородичей связано с генетическими преобразованиями генных сетей, преимущественного отбираемых под влиянием искусственного отбора. Кроме того, начиная с самых ранних геномных исследований доместицированных видов в сравнении с близкородственными дикими обнаруживалось, что искусственный отбор вовлекает в воспроизводство животных с определенными особенностями генов, ассоциированных с функциями иммунной системы (99).

Иммуноглобулины (IgG) выступают ключевым компонентом адаптивной иммунной системы, связывая распознавание антигена с его элиминацией через несколько эффекторных функций. IgG - преобладающий сывороточный иммуноглобулин с широким спектром функциональной активности, включая связывание с антигенами на клеточной поверхности и взаимодействие с системой комплемента $(100,101)$. Оценка генетического разнообразия диких популяций и доместицированных пород по IgG ранее проводилась с помощью серологического анализа их полиморфизма по отношению к спектрам антигенов $(102,103)$, на основании чего было доказано высокое генетическое разнообразие в популяциях кроликов Пиренейского полуострова.

В геномах млекопитающих среди диспергированных повторов широко представлены эндогенные ретровирусы - производные экзогенных вирусов, утратившие инфекционную полноценность, но сохранившие способность воспроизводиться через собственную обратную транскриптазу и расселяться в новые геномные участки. Сравнение домашнего кролика по 
распределению эндогенных ретровирусов (Endogenous Retrovirus, ERV) с предковым европейским подвидом свидетельствует, как правило, о близости их происхождения (21). Ретровирусы интегрируют провирусную копию ДНК в зародышевую линию хозяина и передаются по наследству (104). ERV идентифицируются в геномах хозяина по их сходству с последовательностями представителей экзогенных ретровирусов, принадлежащих к тому же роду (105). Присутствие и перемещения ERV в геноме хозяина приводит к перетасовке геномных последовательностей, которая, в том числе, способствует образованию рекомбинантов эндогенных ретровирусов, а также сохранению отдельных ретровирусных участков, например одиночных длинных терминальных повторов (Long Terminal Repeats, solo-LTR) (106). Широкая распространенность ERV в геномах млекопитающих позволяет использовать гомологичные им последовательности для реконструкции филогенетических взаимоотношений, в том числе для разных групп кроликов (107). В частности, выполнен сравнительный геномный анализ мононуклеотидных замен (SNP) и распределения эндогенных ретровирусов (ERV) у двух подвидов дикого кролика (французский и испанский, O. c. cuniculus и O. c. algirus), а также у домашнего кролика. В геноме европейского кролика выявлено высокое разнообразие ERV, сформированное многочисленными эволюционными событиями (одомашнивание, гибридизация и породообразование) (108). Обнаружено относительно большее сходство распределения ERV между французским подвидом и домашним кроликом по сравнению с испанским подвидом. Суммарно у дикого вида наблюдается большее разнообразие по ERV, чем у домашнего кролика, в то же время выявлено преимущественное размножение отдельных семейств ERV у доместицированных животных, в отличии от исходного подвида.

Молекулярные методы представляют новые инструменты в животноводстве, позволяющие быстро и точно идентифицировать животных, а также оценивать их консолидированность, популяционно-генетические особенности их формирования, уникальность полиморфизма генов и распределения ERV может способствовать разработкам методов управления их генетическими ресурсами (109).

Итак, домашний кролик широко используется для решения ряда сельскохозяйственных и биомедицинских задач. Кроме того, он представляет собой один из редких примеров доместицированного вида, живущего одновременно с предковым диким видом, что открывает уникальные возможности для исследований самого процесса доместикации и собственно «синдрома доместикации», объединяющего виды, принадлежащие удаленным таксонам. Важное условие разработки методов управления генетическими ресурсами этого уникального вида заключается в выявлении фенотипических характеристик и популяционно-генетических и иных биологических особенностей, отличающих домашнего кролика от предкового европейского подвида. Выполненный сравнительный анализ позволяет выделить ряд фенотипических характеристик, дифференцирующий домашнего кролика от предкового вида, а также группу молекулярно-генетических маркеров геномной ДНК для идентификации животных и консолидации генофонда с целью контроля генетических ресурсов и их использовании в селекции с привлечением современных методов. Выявленные закономерности могут быть распространены на других домашних животных, что необходимо как в медико-биологических исследованиях, так и для решения задач производства и переработки продуктов животноводства.

Авторы выражают свою искреннюю благодарность к.б.н. Л.М. Федоровой за 


\title{
${ }_{1}^{1}$ ФБНУ НИИ пушного звероводства и кролиководства им. В.А. Афанасьева, Поступила в редакцию 14 января 2020 года
}

140143 Россия, Московская обл., Раменский р-н, пос. Родники, ул. Трудовая, 6 ,

e-mail: elena.rainis.lis@yandex.ru,gkosovsky@mail.ru, i-kashapova@rambler.ru

2ФГБОУ ВПО Российский государственный

аграрный университет-МСХА им. К.А. Тимирязева,

127550 Россия, г. Москва, ул. Тимирязевская, 49,

e-mail: vigvalery@gmail.com $₫$, tglazko@rambler.ru

Sel'skokhozyaistvennaya biologiya [Agricultural Biology], 2020, V. 55, № 4, pp. 643-658

\section{DOMESTIC RABBIT Oryctolagus cuniculus var. domestica L. AS A MODEL IN THE STUDY OF DOMESTICATION AND BIOMEDICAL RESEARCHES \\ (review)}

\author{
E.S. Shchukina1, G.Yu. Kosovsky1, V.I. Glazko1, 2, I.S. Kashapova1, T.T. Glazko1, 2 \\ ${ }^{1}$ Afanas'ev Research Institute of Fur-Bearing Animal Breeding and Rabbit Breeding, 6, ul. Trudovaya, pos. Rodniki, \\ Ramenskii Region, Moscow Province, 140143 Russia, e-mail elena.rainis.lis@yandex.ru, gkosovsky@mail.ru, \\ i-kashapova@rambler.ru \\ ${ }^{2}$ Timiryazev Russian State Agrarian University-Moscow Agrarian Academy, 49, ul. Timiryazevskaya, Moscow, 127550 \\ Russia, e-mail vigvalery@gmail.com ( $₫$ corresponding author), tglazko@rambler.rusia, e-mail ktqrjp7@yandex.ru \\ ORCID: \\ Shchukina E.S. orcid.org/0000-0002-2465-7184 \\ Kosovskii G.Yu. orcid.org/0000-0003-3808-3086 \\ Kashapova I.S. orcid.org/0000-0002-6360-0025 \\ Glazko T.T. orcid.org/0000-0002-3879-6935
}

Glazko V.I. orcid.org/0000-0002-8566-8717

The authors declare no conflict of interests

Received January 14, 2020 doi: 10.15389/agrobiology.2020.4.643eng

\section{Abstract}

The domestic rabbit (Oryctolagus cuniculus var. domestica L.) belongs to the few domesticated species in which the wild ancestral species exists simultaneously with the domesticated one (M. Carneiro, 2014) that allows us to study the mechanisms underlying the processes of domestication. It should be noted that the genetic basis of domestication syndrome is still insufficiently studied (M.A. Zeder, 2006-2017). It is assumed that domestication is a unique form of symbiosis between humans and domesticated species that form a common habitat niche (M.A. Zeder, 2012). Research of symbiotic partners of such a niche allows us to accumulate information about the mechanisms of adaptation to it, including humans. In this regard, it is difficult to overestimate the importance of studying the domestic rabbit, because it has remained one of the main models in biomedical research for many decades (K.M. El-Bayomi, 2013). The unique physiological features of the rabbit explain its widespread use in the study of many human diseases. At the same time, we have not found any works that systematize current information on the fundamental biology of this domesticated species in comparison with its wild ancestral form. The purpose of this review is to summarize data on the population genetic structure (M. Carneiro, 2014; A.D. Stock, 1976), distribution of genomic elements (M. Carneiro, 2011), composition of microbiomes (M.S. Gómez-Conde, 2009), morphometric characteristics and physiological features (S.N. Bogolyubskii, 1959) of the domestic rabbit and ancestral subspecies of the European rabbit, including those that determine the value of $O$. cuniculus var. domestica not only as an economically valuable species, but also as a model object in various fields of biomedicine. The presented comparative analysis allows us to identify a number of phenotypic characteristics (J.L. Hendrikse, 2007; I. Brusini, 2018; P.S. Ungar, 2010), as well as a group of molecular genetic markers of genomic DNA, differentiating the domestic rabbit from the ancestral species (M. Sparwel, 2019). Distribution of alleles of different mobile genetic elements, microsatellites, separate structural genes involved in the domestication process of domestic rabbit, can improve the efficiency of genetic resources management of not only this species but also other objects that are used in biomedical research, and for solving problems of selection work.

Keywords: domestication syndrome, wild rabbits, domestic rabbits, DNA markers, endogenous retroviruses, polylocus genotyping, microbiota.

\section{REFERENCES}

1. Glazko V.I. Gene and genomic levels of domestication signature (review). Agricultural Biology 
[Sel'skokhozyaistvennaya biologiya], 2018, 53(4): 659-672 (doi: 10.15389/agrobiology.2018.4.659eng).

2. Zeder M.A., Emshwiller E., Smith B.D., Bradley D.G. Documenting domestication: the intersection of genetics and archaeology. Trends in Genetics, 2006, 22(3): 139-155 (doi: 10.1016/j.tig.2006.01.007).

3. Zeder M.A. The domestication of animals. Journal of Anthropological Research, 2012, 68(2): 161190 (doi: 10.3998/jar.0521004.0068.201).

4. Zeder M.A. Domestication as a model system for the extended evolutionary synthesis. Interface Focus, 2017, 7(5): 20160133 (doi: 10.1098/rsfs.2016.0133).

5. Lewis S.L., Maslin M.A. Defining the Anthropocene. Nature, 2015, 519(7542): 171-180 (doi: $10.1038 /$ nature 14258).

6. El-Bayomi Kh.M., Awad A., Saleh A.A. Genetic diversity and phylogenetic relationship among some rabbit breeds using random amplified polymorphic DNA markers. Life Science Journal, 2013, 10(1): 1449-1457.

7. Rybakova A.V., Makarova M.N., Makarov V.G. Mezhdunarodnyi vestnik veterinarii, 2016, 4: 102106 (in Russ.).

8. Sergienko I.V. Ateroskleroz i dislipidemii, 2011, 1: 57-65 (in Russ.).

9. Carneiro M., Afonso S., Geraldes A., Garreau H., Bolet G., Boucher S., Tircazes A., Queney G., Nachman M.W., Ferrand N. The genetic structure of domestic rabbits. Molecular Biology and Evolution, 2011, 28(6): 1801-1816 (doi: 10.1093/molbev/msr003).

10. Maksimenko O.G., Deikin A.V., Khodarovich Yu.M., Georgiev P.G. Acta Naturae, 2013, 1(16): 33-47 (in Russ.).

11. Whitman B.D. Domestic rabbits \& their histories: breeds of the world. Overland Park, KS: Leathers Publishing, 2004.

12. Weisbroth S.H. Chapter 14 Neoplastic diseases. In: The biology of the laboratory rabbit. S.H. Weisbroth, R.E. Flatt, A.L. Kraus (eds.). Academic Press, New York, 1974: 332-376.

13. Lindsey J., Fox R. Inherited disease and variations. In: The biology of the laboratory rabbit. P. Manning (ed.), D. Ringler, C. Newcomer (series eds.). Academic Press, San Diego (CA), 1994: 293-319.

14. Lebas F., Coudert P., de Rochambeau H., Thébault R.G. The rabbit: husbandry, health and production. FAO Animal Production and Health Series № 21. FAO, Rome, 1997.

15. Bosze Z., Hiripi L., Carnwath J.W., Niemann H. The transgenic rabbit as model for human diseases and as a source of biologically active recombinant proteins. Transgenic Research, 2003, 12(5): 541-553 (doi: 10.1023/A:1025816809372).

16. Fan J.L., Watanabe T. Transgenic rabbits as therapeutic protein bioreactors and human disease models. Pharmacology \& Therapeutics, 2003, 99(3): 261-282 (doi: 10.1016/S01637258(03)00069-X).

17. Houdebine L.M., Jolivet G., Ripoli P.J. Transgenic rabbits to prepare pharmaceutical proteins. In: Rabbit biotechnology: rabbit genomics, transgenesis, cloning and models. L.M. Houdebine, J. Fan (eds.). Springer, Dordrecht, 2009: 65-75 (doi: 10.1007/978-90-481-2227-1 8).

18. Rogel-Gaillard C., Ferrand N., Hayes H. Rabbit. In: Genome mapping and genomics in domestic animals. N.E. Cockett, C. Kole. Springer, 2009: 165-230.

19. El-Sabrout K., Aggag S., JBF de Souza Jr. Some recent applications of rabbit biotechnology - a review. Animal Biotechnology, 2018, 31(1): 76-80 (doi: 10.1080/10495398.2018.1539005).

20. Gunia M., David I., Hurtaud J., Maupin M., Gilbert H., Garreau H. Genetic parameters for resistance to non-specific diseases and production traits measured in challenging and selection environments; application to a rabbit case. Frontiers in Genetics, 2018, 9: 467 (doi: 10.3389/fgene.2018.00467).

21. Carneiro M., Rubin C., Palma F., Albert F., Alföldi J., Barrio A.M., Pielberg G., Rafati N., Sayyab S., Turner-Maier J., S Younis., Afonso S., Aken B., Alves J.M., Barrell D., Bolet G., Boucher S., Burbano H.A., Campos R., Chang J.L., Duranthon V., Fontanesi L., Garreau H., Heiman D., Johnson J., Mage R.G., Peng Z., Queney G., Rogel-Gaillard C., Ruffier M., Searle S., Villafuerte R., Xiong A., Young S., Forsberg-Nilsson K., Good J.M., Lander E.S., Ferrand N., Lindblad-Toh K., Andersson L. Rabbit genome analysis reveals a polygenic basis for phenotypic change during domestication. Science, 2014, 345(6200): 1074-1079 (doi: 10.1126/science.1253714).

22. Fontanesi L., Di Palma F., Flicek P., Smith A.T., Thulin C.G., Alves P.C., Lagomorph Genomics Consortium. LaGomiCs-Lagomorph Genomics Consortium: an international collaborative effort for sequencing the genomes of an entire Mammalian order. Journal of Heredity, 2016, 107(4): 295-308 (doi: 10.1093/jhered/esw010).

23. Linnaeus C. Systema naturae, per regna tria naturae, secundum classes, ordines, genera, species, cum characteribus, differentiis, synonymis, locis. Tomus I. Holmiae, Impensis Direct Laurentii Salvii, 1758 (doi: 10.5962/bhl.title.542).

24. O’Leary M.A., Bloch J.I., Flynn J.J., Gaudin T.J., Giallombardo A., Giannini N.P., Goldberg S.L., Kraatz B.P., Luo Z.X., Meng J., Ni X., Novacek M.J., Perini F.A., Randall Z.S., Rougier G.W., Sargis E.J., Silcox M.T., Simmons N.B., Spaulding M., Velazco P.M., 
Weksler M., Wible J.R., Cirranello A.L. The placental mammal ancestor and the post-K-Pg radiation of placentals. Science, 2013, 339(6120): 662-667 (doi: 10.1126/science.1229237).

25. Stock A.D. Chromosome banding pattern relationships of hares, rabbits, and pikas (order Lagomorpha). Cytogenetic and Genome Research, 1976, 17(2): 78-88 (doi: 10.1159/000130692).

26. Korstanje R., O'Brien P.C.M., Yang F., Rens W., Bosma A.A., van Lith H.A., FergusonSmith M.A. Complete homology maps of the rabbit (Oryctolagus cuniculus) and human by reciprocal chromosome painting. Cytogenetic and Genome Research, 1999, 86(3-4): 317-322 (doi: 10.1159/000015325).

27. Robinson T.J., Yang F., Harrison W.R. Chromosome painting refines the history of genome evolution in hares and rabbits (order Lagomorpha). Cytogenetic and Genome Research, 2002, 96(14): 223-227 (doi: 10.1159/000063034).

28. Beklemisheva V.R., Romanenko S.A., Biltueva L.S., Trifonov V.A., Vorobieva N.V., Serdukova N.A., Rubtsova N.V., Brandler O.V., O’Brien P.C., Yang F., Stanyon R., FergusonSmith M.A., Graphodatsky A.S. Reconstruction of karyotype evolution in core Glires. I. The genome homology revealed by comparative chromosome painting. Chromosome Res., 2011, 19(4): 549-565 (doi: 10.1007/s10577-011-9210-y).

29. Ho S., Larson G. Molecular clocks: when times are a-changin. Trends Genet., 2006, 22(2): 7983 (doi: 10.1016/j.tig.2005.11.006).

30. Sana M. Domestication of animals in the Iberian Peninsula. In: The origins and spread of domestic animals in Southwest Asia and Europe /S. Colledge, J. Conolly, K. Dobney, K. Manning, S. Shennan (eds). Left Coast Press, Inc, 2013, 195-221.

31. Quintana J., Ramis D., Bover P. Primera datació d'un mamífer no autòcton (Oryctolagus cuniculus [Linnaeus, 1758]) (Mammalia: Lagomorpha) del jaciment holocènic del Pas d'en Revull (barranc d'Algendar, Ferreries). Revista de Menorca, 2016, 95: 185-200.

32. Clutton-Brock J. A natural history of domesticated mammals. Cambridge University Press, Cambridge, UK, 1999.

33. Lewis S.T., Short C. A Latin dictionary (importacion). Oxford University Press, 1963.

34. Varronis M.T. Rerum Rusticarum Libri Tres /G. Goetz (ed.). Lipsiae, Teubner, 1929.

35. Nachtsheim H. Vom Wildtier zum Haustier. Berlin: Alfred Metzner, 1936.

36. Méniel P. Callou C. (2003) De la garenne au clapier: etude archeozoologique du Lapin en Europe occidentale. Bulletin de la Société préhistorique française, 2004, 101(2): 371-372.

37. Irving-Pease E.K., Frantz L.A.F., Sykes N., Callou C., Larson G. Rabbits and the specious origins of domestication. Trends in Ecology \& Evolution, 2018, 33(3): 149-152 (doi: 10.1016/j.tree.2017.12.009).

38. Vigne J.-D. The origins of animal domestication and husbandry: a major change in the history of humanity and the biosphere. Comptes Rendus Biologies, 2011, 334(3): 171-181 (doi: 10.1016/j.crvi.2010.12.009).

39. Price E.O. Behavioral development in animals undergoing domestication. Applied Animal Behaviour Science, 1999, 65(3): 245-271 (doi: 10.1016/S0168-1591(99)00087-8).

40. Bogolyubskii S.N. Proiskhozhdenie i preobrazovanie domashnikh zhivotnykh [The origin and transformation of domestic animals]. Moscow, 1959 (in Russ.).

41. Moore W.J. The mammalian skull. Cambridge University Press, Cambridge, UK, 1981.

42. Sánchez-Villagra M.R., Segura V., Geiger M., Heck L., Veitschegger K., Flores D. On the lack of a universal pattern associated with mammalian domestication: differences in skull growth trajectories across phylogeny. Royal Society Open Science, 2017, 4(10): 170876 (doi: 10.1098/rsos. 170876).

43. Wilkins A.S., Wrangham R.W., Fitch W.T. The 'domestication syndrome' in mammals: a unified explanation based on neural crest cell behavior and genetics. Genetics, 2014, 197(3): 795-808 (doi: 10.1534/genetics.114.165423).

44. Hendrikse J.L., Parsons T.E., Hallgrímsson B. Evolvability as the proper focus of evolutionary developmental biology. Evolution \& Development, 2007, 9(4): 393-401 (doi: 10.1111/j.1525142X.2007.00176.x).

45. Wayne R.K. Cranial morphology of domestic and wild canids: the influence of development on morphological change. Evolution, 1986, 40(2): 243-261 (doi: 10.1111/j.1558-5646.1986.tb00467.x).

46. Gilyarov M.S. Biologicheskii entsiklopedicheskii slovar' [Encyclopedic dictionary of Biology]. Moscow, 1986 (in Russ.).

47. Richardson M.K. Vertebrate evolution: the developmental origins of adult variation. BioEssays, 1999, 21(7): 604-613 (doi: 10.1002/(SICI)1521-1878(199907)21:7<604::AID-BIES9>3.0.CO;2-U).

48. Kruska D.C.T. On the evolutionary significance of encephalization in some eutherian mammals: effects of adaptive radiation, domestication, and feralization. Brain, Behavior and Evolution, 2005, 65(2): 73-108 (doi: 10.1159/000082979).

49. Agren T., Engman J., Frick A., Björkstrand J., Larsson E., Furmark T., Fredrikson M. Disruption of reconsolidation erases a fear memory trace in the human amygdala. Science, 2012, 337(6101): 1550-1552 (doi: 10.1126/science.1223006).

50. Davidson R.J., Putnam K.M., Larson C.L. Dysfunction in the neural circuitry of emotion regulation: a possible prelude to violence. Science, 2000, 289(5479): 591-594 (doi: 
10.1126/science.289.5479.591).

51. Brusini I., Carneiro M., Wang C., Rubin C., Ring H., Afonso S., Blanco-Aguiar J.A., Ferrand N., Rafati N., Villafuerte R., Smedby Ö., Damberg P., Hallböök F., Fredrikson M., Andersson L. Changes in brain architecture are consistent with altered fear processing in domestic rabbits. PNAS, 2018, 115(28): 7380-7385 (doi: 10.1073/pnas.1801024115).

52. Ungar P.S. Mammal. Teeth: origin, evolution, and diversity. The Johns Hopkins University Press: Baltimore, 2010.

53. Damuth J., Janis C.M. On the relationship between hypsodonty and feeding ecology in ungulate mammals, and its utility in palaeoecology. Biological Reviews, 2011, 86(3): 733 758 (doi: 10.1111/j.1469-185x.2011.00176.x).

54. Williams S.H., Kay R.F. A comparative test of adaptive explanations for hypsodonty in ungulates and rodents. Journal of Mammalian Evolution, 2001, 8(3): 207-229 (doi: 10.1023/A:1012231829141).

55. Böhmer E. Warum Leiden Hauskaninchen so Häufig an Gebiss-und Verdauungsproblemen? Ein Ratgeber für die Ernährung von Kaninchen. Curoxray, München, 2014.

56. Okuda A., Hori Y., Ichihara N., Asari M., Wiggs R.B. Comparative observation of skeletal-dental abnormalities in wild, domestic, and laboratory rabbits. J. Vet. Dent., 2007, 24(4): 224-229 (doi: 10.1177/089875640702400403).

57. Koenigswald W.V. Diversity of hypsodont teeth in mammalian dentitions - construction and classification. Palaeontographica, Abt. A: Palaeozoology - Stratigraphy, 2011, 294(1-3): 63-94 (doi:10.1127/pala/294/2011/63).

58. Evolution of the Rodents: advances in phylogeny, functional morphology and development. P.G. Cox, L. Hautier (eds.). Cambridge University Press, Cambridge, 2015 (doi: 10.1017/CBO9781107360150).

59. Schmidt-Kittler N. Feeding specializations in rodents. Senckenbergiana Lethaea, 2002, 82(1): 141 152 (doi: 10.1007/BF03043780).

60. Ge D., Yao L., Xia L., Zhang Z., Yang Q. Geometric morphometric analysis of skull morphology reveals loss of phylogenetic signal at the generic level in extant lagomorphs (Mammalia: Lagomorpha). Contributions to Zoology, 2015, 84(4): 267-284 (doi: 10.1163/18759866-08404001).

61. Kraatz B.P., Sherratt E., Bumacod N., Wedel M.J. Ecological correlates to cranial morphology in Leporids (Mammalia, Lagomorpha). PeerJ, 2015, 3: e844 (doi: 10.7717/peerj.844).

62. Koenigswald W.V, Anders U., Engels S., Schultz J.A., Ruf I. Tooth morphology in fossil and extant Lagomorpha (Mammalia) reflects different mastication patterns. Journal of Mammalian Evolution, 2010, 17(4): 275-299 (doi: 10.1007/s10914-010-9140-z).

63. Watson P.J., Groning F., Curtis N., Fitton L.C., Herrel A., McCormack S.W., Fagan M.J. Masticatory biomechanics in the rabbit: a multi-body dynamics analysis. J. R. Soc. Interface, 2014, 11(99): 20140564 (doi: 10.1098/rsif.2014.0564).

64. Ardran G.M., Kemp F.H., Ride W.D.L. A radiographic analysis of mastication and swallowing in the domestic rabbit: Oryctolagus cuniculus. Proceedings of the Zoological Society of London, 1958, 130(2): 257-274 (doi: 10.1111/j.1096-3642.1958.tb00573.x).

65. Weijs W.A., Dantuma R. Functional anatomy of the masticatory apparatus in the rabbit (Oryctolagus cuniculus L.). Netherlands Journal of Zoology, 1981, 31(3): 99-147 (doi: 10.1163/002829680X00212).

66. Weijs W.A., Brugman P., Grimbergen C.A. Jaw movements and muscle activity during mastication in growing rabbits. Anat. Rec., 1989, 224(3): 407-416 (doi: 10.1002/ar.1092240309).

67. Ravosa M.J., Scott J.E., McAbee K.R., Veit A.J., Fling A.L. Chewed out: an experimental link between food material properties and repetitive loading of the masticatory apparatus in mammals. PeerJ, 2015, 3: e1345 (doi: 10.7717/peerj.1345).

68. Böhmer E. Dentistry in rabbits and rodents. Wiley Blackwell, Chichester, 2015.

69. Böhmer C., Böhmer E. Shape variation in the craniomandibular system and prevalence of dental problems in domestic rabbits: a case study in evolutionary veterinary science. Vet Sci., 2017, 4(1): 5 (doi: 10.3390/vetsci4010005).

70. Yatsunenko T., Rey F.E., Manary M.J., Trehan I., Dominguez-Bello M.G., Contreras M., Magris M., Hidalgo G., Baldassano R N., Anokhin A.P., Heath A.C., Warner B., Reeder J., Kuczynski J., Caporaso J.G., Lozupone C.A., Lauber C., Clemente J.C., Knights D., Knigh, R., Gordon J.I. Human gut microbiome viewed across age and geography. Nature, 2012, 486(7402): $222-$ 227 (doi: 10.1038/nature11053).

71. Ventura M., Turroni F., Motherway M.O., MacSharry J., van Sinderen D. Host-microbe interactions that facilitate gut colonization by commensal bifidobacteria. Trends Microbiol., 2012, 20(10): 467-476 (doi: 10.1016/j.tim.2012.07.002).

72. Milani C., Mangifesta M., Mancabelli L., Lugli G.A., James K., Duranti S., Turron, F., Ferrario C., Ossiprandi M.C., van Sinderen D., Ventura M. Unveiling bifidobacterial biogeography across the mammalian branch of the tree of life. ISME J., 2017, 11(12): 2834-2847 (doi: 10.1038/ismej.2017.138).

73. Stott P. Use of space by sympatric European hares (Lepus europaeus) and European rabbits (Oryctolagus cuniculus) in Australia. Mammalian Biology., 2003, 68(5): 317-327 (doi: 10.1078/1616-5047-00099).

74. Wallage-Drees J.M., Deinum B. Quality of the diet selected by wild rabbits (Oryctolagus cuniculus L.) in autumn and winter. Netherlands Journal of Zoology, 1986, 36(4): 438-448 
(doi: 10.1163/002829686X00162).

75. Abecia L., Rodríguez-Romero N., Yacez-Ruiz D.R., Fondevila M. Biodiversity and fermentative activity of caecal microbial communities in wild and farm rabbits from Spain. Anaerobe, 2012, 18(3): 344-349 (doi: https://doi.org/10.1016/j.anaerobe.2012.04.004).

76. Gómez-Conde M.S., Pérez de Rozas A., Badiola I., Pérez-Alba L., de Blas C., Carabaco R., García J. Effect of neutral detergent soluble fibre on digestion, intestinal microbiota and performance in twenty-fiveday old weaned rabbits. Livestock Science, 2009, 125(2-3): 192-198 (doi: 10.1016/j.livsci.2009.04.010).

77. Gidenne T., Jehl N., Lapanouse A., Segura M. Inter-relationship of microbial activity, digestion and gut health in the rabbit: effect of substituting fibre by starch in diets having a high proportion of rapidly fermentable polysaccharides. British Journal of Nutrition, 2004, 92(1): 95-104 (doi: 10.1079/BJN20041173).

78. Pinheiro V., Outor-Monteiro D., Mourão J.L., Cone J.W., Lourenço A.L. Effects of animal type (wild vs. domestic) and diet alfalfa level on intake and digestibility of European adult rabbits (Oryctolagus cuniculus). J. Anim. Physiol. Anim. Nutr., 2018, 102(1): e460-e467 (doi: 10.1111/jpn.12774).

79. Carneiro M., Ferrand N., Nachman M.W. Recombination and speciation: loci near centromeres are more differentiated than loci near telomeres between subspecies of the European rabbit (Oryctolagus cuniculus). Genetics, 2009, 181(2): 593-606 (doi: 10.1534/genetics. 108.096826).

80. Geraldes A., Ferrand N., Nachman M.W. Contrasting patterns of introgression at X-linked loci across the hybrid zone between subspecies of the European rabbit (Oryctolagus cuniculus). Genetics, 2006, 173(2): 919-933 (doi: 10.1534/genetics.105.054106).

81. Kuznetsov V.M. Problemy biologii produktivnykh zhivotnykh, 2014, 4: 80-104 (in Russ.).

82. Anderson C.N.K., Ramakrishnan U., Chan Y.L., Hadly E.A. A population genetics model for data from multiple populations and points in time. Bioinformatics, 2004, 21(8): 1733-1734 (doi: 10.1093/bioinformatics/bti154).

83. Oliver F., Christians J.K., Liu X., Rhind S., Verma V., Davison C., Brown S.D., Denny P., Keightley P.D. Regulatory variation at glypican-3 underlies a major growth QTL in mice. PLoS Biology, 2005, 3(5): e135 (doi: 10.1371/journal.pbio.0030135).

84. Pilia G., Hughes-Benzie R.M., MacKenzie A., Baybayan P., Chen E.Y., Huber R., Neri G., Cao A., Forabosco A., Schlessinger D. Mutations in GPC3, a glypican gene, cause the SimpsonGolabi-Behmel overgrowth syndrome. Nat. Genet., 1996, 12(3): 241-247 (doi: 10.1038/ng0396-241).

85. Brandvain Y., Wright S.I. The limits of natural selection in a nonequilibrium world. Trends Genet., 2016, 32(4): 201-210 (doi: 10.1016/j.tig.2016.01.004).

86. Geraldes A., Rogel - Gaillard C., Ferrand N. High levels of nucleotide diversity in the European rabbit (Oryctolagus cuniculus) SRY gene. Animal Genetics, 2005, 36(4): 349-351 (doi: 10.1111/j.13652052.2005.01300.x).

87. Khaitovich P., Hellmann I., Enard W., Nowick K., Leinweber M., Franz H., Weiss G., Lachmann M., Pääbo S. Parallel patterns of evolution in the genomes and transcriptomes of humans and chimpanzees. Science, 2005, 309(5742): 1850-1854 (doi: 10.1126/science.1108296).

88. Candille S.I., Kaelin C.B., Cattanach B.M., Yu B., Thompson D.A., Nix M.A., Kerns J.A., Schmutz S.M., Millhauser G.L., Barsh G.S. A beta-defensin mutation causes black coat color in domestic dogs. Science, 2007, 318(5855): 1418-1423 (doi: 10.1126/science.1147880).

89. Fang M., Larson G., Soares Ribeiro H., Li N., Andersson L. Contrasting mode of evolution at a coat color locus in wild and domestic pigs. PLoS Genet., 2009, 5(1): e1000341 (doi: 10.1371/journal.pgen.1000341).

90. Ludwig A., Pruvost M., Reissmann M., Benecke N., Brockmann G.A., Castacos P., Cieslak M., Lippold S., Llorente L., Malaspinas A., Slatkin M., Hofreiter M. Coat color variation at the beginning of horse domestication. Science, 2009, 324(5926): 485 (doi: 10.1126/science.1172750).

91. Kerje S., Lind J., Schütz K., Jensen P., Andersson L. Melanocortin 1-receptor (MC1R) mutations are associated with plumage color in chicken. Animal Genetics, 2003, 34(4): 241-248 (doi: 10.1046/j.1365-2052.2003.00991.x).

92. Stern D.L., Orgogozo V. The loci of evolution: how predictable is genetic evolution. Evolution, 2008, 62(9): 2155-2177 (doi: 10.1111/j.1558-5646.2008.00450.x).

93. Letko A., Ammann B., Jagannathan V., Henkel J., Leuthard F., Schelling C., Carneiro M., Drцgemüller C., Leeb T. A deletion spanning the promoter and first exon of the hair cyclespecific ASIP transcript isoform in black and tan rabbits. Animal Genetics, 2019, 51(1): 137-140 (doi: 10.1111/age.12881).

94. Leung C.L., Green K.J., Liem R.K. Plakins: a family of versatile cytolinker proteins. Trends in Cell Biology, 2002, 12(1): 37-45 (doi: 10.1016/s0962-8924(01)02180-8).

95. Jacobs D.T., Weigert R., Grode K.D., Donaldson J.G., Cheney R.E. Myosin Vc is a molecular motor that functions in secretory granule trafficking. Molecular Biology of the Cell, 2009, 20(21): 4471-4488 (doi: 10.1091/mbc.E08-08-0865).

96. Wray G.A. The evolutionary significance of cis-regulatory mutations. Nature Reviews Genetics, 2007, 8(3): 206-216 (doi: 10.1038/nrg2063).

97. Lindblad-Toh K., Wade C.M., Mikkelsen T.S., Karlsson E.K., Jaffe D.B., Kamal M., Clamp M., 
Chang J.L., Kulbokas 3rd E.J., Zody M.C., Mauceli E., Xie X., Breen M., Wayne R.K., Ostrander E.A., Ponting C.P., Galibert F., Smith D.R., DeJong P.J., Kirkness E., Alvarez P., Biagi T., Brockman W., Butler J., Chin C., Cook A., Cuff J., Daly M. J., DeCaprio D., Gnerre S., Grabherr M., Kellis M., Kleber M., Bardeleben C., Goodstadt L., Heger A., Hitte C., Kim L., Koepfli K., Parker H.G., Pollinger J.P., Searle S.M.J., Sutter N.B., Thomas R., Webber C., Baldwin J., Abebe A., Abouelleil A., Aftuck L., Ait-Zahra M., Aldredge T., Allen N., An P., Anderson S., Antoine C., Arachchi H., Aslam A., Ayotte L., Bachantsang P., Barry A., Bayul T., Benamara M., Berlin A., Bessette D., Blitshteyn B., Bloom T., Blye J., Boguslavskiy L., Bonnet C., Boukhgalter B., Brown A., Cahill P., Calixte N., Camarata J., Cheshatsang Y., Chu J., Citroen M., Collymore A., Cooke P., Dawoe T., Daza R., Decktor K., DeGray S., Dhargay N., Dooley K., Dooley K., Dorje P., Dorjee K., Dorris L., Duffey N., Dupes A., Egbiremolen O., Elong R., Falk J., Farina A., Faro S., Ferguson D., Ferreira P., Fisher S., FitzGerald M., Foley K., Foley C., Franke A., Friedrich D., Gage D., Garber M., Gearin G., Giannoukos G., Goode T., Goyette A., Graham J., Grandbois E., Gyaltsen K., Hafez N., Hagopian D., Hagos B., Hall J., Healy C., Hegarty R., Honan T., Horn A., Houde N., Hughes L., Hunnicutt L., Husby M., Jester B., Jones C., Kamat A., Kanga B., Kells C., Khazanovich D., Kieu A.C., Kisner P., Kumar M., Lance K., Landers T., Lara M., Lee W., Leger J., Lennon N., Leuper L., LeVine S., Liu J., Liu X., Lokyitsang Y., Lokyitsang T., Lui A., Macdonald J., Major J., Marabella R., Maru K., Matthews C., McDonough S., Mehta T., Meldrim J., Melnikov A., Meneus L., Mihalev A., Mihova T., Miller K., Mittelman R., Mlenga V., Mulrain L., Munson G., Navidi A., Naylor J., Nguyen T., Nguyen N., Nguyen C., Nguyen T., Nicol R., Norbu N., Norbu C., Novod N., Nyima T., Olandt P., O’Neill B., O’Neill K., Osman S., Oyono L., Patti C., Perrin D., Phunkhang P., Pierre F., Priest M., Rachupka A., Raghuraman S., Rameau R., Ray V., Raymond C., Rege F., Rise C., Rogers J., Rogov P., Sahalie J., Settipalli S., Sharpe T., Shea T., Sheehan M., Sherpa N., Shi J., Shih D., Sloan J., Smith C., Sparrow T., Stalker J., StangeThomann N., Stavropoulos S., Stone C., Stone S., Sykes S., Tchuinga P., Tenzing P., Tesfaye S., Thoulutsang D., Thoulutsang Y., Topham K., Topping I., Tsamla T., Vassiliev H., Venkataraman V., Vo A., Wangchuk T., Wangdi T., Weiand M., Wilkinson J., Wilson A., Yadav S., Yang S., Yang X., Young G., Yu Q., Zainoun J., Zembek L., Zimmer A., Lander E.S. Genome sequence, comparative analysis and haplotype structure of the domestic dog. Nature, 2005, 438(7069): 803-819 (doi: 10.1038/nature04338).

98. Casares-Crespo L., Fernández-Serrano P., Viudes-de-Castro M.P. Proteomic characterization of rabbit (Oryctolagus cuniculus) sperm from two different genotypes. Theriogenology, 2019, 128: 140148 (doi: 10.1016/j.theriogenology.2019.01.026).

99. Diamond J. Evolution, consequences and future of plant and animal domestication. Nature, 2002, 418(6898): 700-707 (doi: 10.1038/nature01019).

100. Pinheiro A., Woof J.M., Almeida T., Abrantes J., Alves P. C., Gortázar C., Esteves P.J. Leporid immunoglobulin $\mathrm{G}$ shows evidence of strong selective pressure on the hinge and $\mathrm{CH} 3$ domains. Open Biology, 2014, 4(9): 140088 (doi: 10.1098/rsob.140088).

101. Pinheiro A., Almeida T., Esteves P.J. Survey of genetic diversity of IgG in wild and domestic rabbits. International Journal of Immunogenetics, 2015, 42(5): 364-367 (doi: 10.1111/iji. 12222).

102. Dubiski S. Immunochemistry and genetics of a "new" allotypic specificity Ae14 of rabbit gammaG immunoglobulins: recombination in somatic cells. J. Immunol., 1969, 103(1): 120-128.

103. Esteves P.J., Carmo C., Godinho R., van der Loo W. Genetic diversity at the hinge region of the unique immunoglobulin heavy gamma (IGHG) gene in leporids (Oryctolagus, Sylvilagus and Lepus). International Journal of Immunogenetics, 2006, 33(3): 171-177 (doi: 10.1111/j.1744313x.2006.00588.x).

104. Jern P., Coffin J.M. Effects of retroviruses on host genome function. Annual Review of Genetics, 2008, 42: 709-732 (doi: 10.1146/annurev.genet.42.110807.091501).

105. Sperber G.O., Airola, T., Jern, P., Blomberg, J. Automated recognition of retroviral sequences in genomic data-RetroTector. Nucleic Acids Research, 2007, 35(15): 4964-4976 (doi: 10.1093/nar/gkm515).

106. Rivas-Carrillo S.D., Pettersson M.E., Rubin C., Jern P. Whole-genome comparison of endogenous retrovirus segregation across wild and domestic host species populations. PNAS, 2018, 115(43): 11012-11017 (doi: 10.1073/pnas.1815056115).

107. Sparwel M., Doronina L., Churakov G., Stegemann A., Brosius J., Robinson T.J., Schmitz J. The volcano rabbit in the phylogenetic network of Lagomorphs. Genome Biology and Evolution, 2019, 11(1): 11-16 (doi: 10.1093/gbe/evy257).

108. Rafati N., Blanco-Aguiar J.A., Rubin C J., Sayyab S., Sabatino S.J., Afonso S., Feng C., Alves P.C., Villafuerte R., Ferrand N., Andersson L., Carneiro M. A genomic map of clinal variation across the European rabbit hybrid zone. Molecular Ecology, 2018, 27(6): 1457-1478 (doi: 10.1111/mec.14494).

109. Fulton J.E. Molecular genetics in a modern poultry breeding organization. World's Poultry Science Journal, 2008, 64(2): 171-176 (doi: 10.1017/S0043933907001778). 